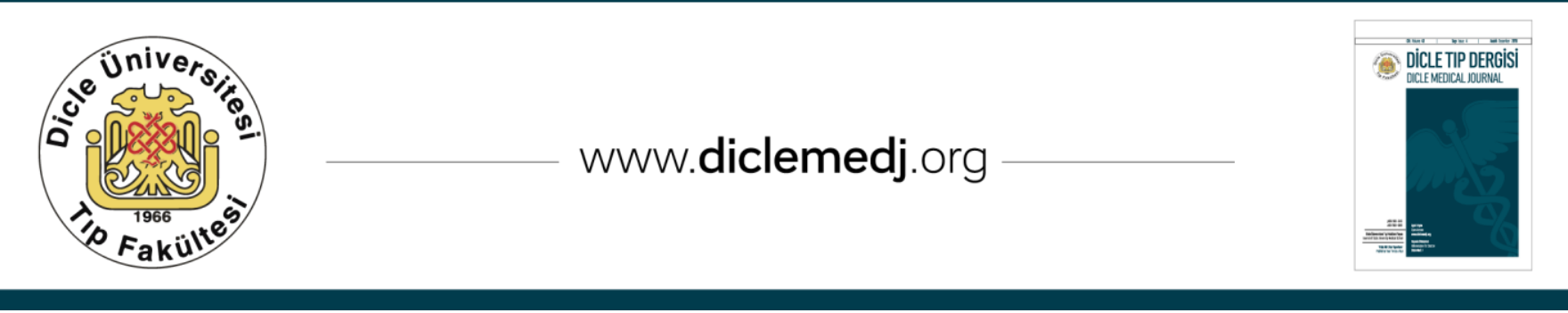

Özgün Araştırma / Original Article

\title{
Huntington Hastalığında Dikkat Fonksiyonlarının Değerlendirilmesi
}

\author{
Murat Gültekin1, Ayten Ekinci²
}

1 ErciyesÜniversitesi Tıp Fakültesi Nöroloji Ana Bilim Dalı 38039 Talas, Kayseri, Türkiye ORCID: 0000-0002-0609-4269

2 ErciyesÜniversitesi Tıp Fakültesi Nöroloji Ana Bilim Dalı 38039 Kayseri, Türkiye ORCID: 0000-0001-8639-9451

Geliş: 29.07.2017, Revizyon: 03.10.2017, Kabul Tarihi: 05.10.2017

Özet

Giriş: Huntington hastalığı $(\mathrm{HH})$ otozomal dominant geçişli nörodejeneratif bir hastalıktır. HH'li hastalar üçlü klinik triada sahiptir. Bunlar; motor, kognitif ve psikiyatrik özelliklerdir. Dikkat fonksiyonları HH'li hastalarda klinik seyir başladıktan sonra bozulmaya başlamaktadır. Bu çalışmanın amacı; genetik tanıları doğrulanmış olan HH'li hastalarda dikkat fonksiyonlarının kontrol grubu ile karşılaştırarak değerlendirmektir.

Yöntemler: Çalışmaya HH tanısı genetik test ile doğrulanan 15 HH ve 15 sağlıklı kontrol grubu alındı. Katılımcıların bilișsel ișlevlerini değerlendirmeye yönelik Stroop Testi, İz Sürme Testi (IST) ve Mini Mental Durum Değerlendirmesi (MMDM) testlerini kapsayan bir batarya oluşturulup uygulandı.

Bulgular: Her iki grup 9 erkek ve 6 kadın bireyden oluşuyordu. Hasta ve kontrol grubunun yaş ortalaması 48 bulundu. Hasta grubunda ortalama hastalık süresi 5 yıldı (1-16). Hastaların ortalama CAG tekrar sayıları $43.3 \pm 3.5$ (40-50) bulundu. Hasta grubunda dikkat test skorları hem İST-A testinde ve hem de stroop testinde istatiksel olarak daha kötü bulundu. $\mathrm{Bu}$ verilere ilave olarak, hastaların CAG tekrar sayıları artıkça, tüm test süreleri de daha fazla zaman alıyordu. Ayrıca CAG sayısı ile hastalık süresi ve total motor skorları arasında pozitif korelasyon bulundu. Bu durum istatistiksel olarak anlamlı bulundu

Sonuç: HH'da dikkat fonksiyonları kliniği hafif olan ve CAG tekrar sayısı az olan olgularda bile bozulmaktadır. Bu durum sadece kognisyonu değil aynı zamanda motor fonksiyonları da olumsuz etkileyebilmektedir.

Anahtar kelimeler: Huntington hastalı̆̆ı, dikkat, kognisyon.

DOI: $10.5798 /$ dicletip.362415

Yazışma Adresi / Correspondence: Murat Gültekin, Erciyes Üniversitesi Tıp Fakültesi Nöroloji Ana Bilim Dalı 38039 Kayseri, Türkiye e-mail: gultekin@erciyes.edu.tr 


\title{
Evaluation of attention functions in Huntington's disease
}

\begin{abstract}
Objective: Huntington's disease (HD) is an autosomal dominant inherited neurodegenerative disease. Patients with HD have a triple clinical triad. These are motor, cognitive and psychiatric features. Attention functions are beginning to deteriorate in patients with HD after the clinical course begins. The purpose of this study is compared of attention functions in HD patients who genetic diagnosesconfirmed and control group.

Methods: Fifteen patients with HD and 15 healthy control group confirmed were included in the study. A battery containing the Stroop test, trail making test and Mini Mental State Examination (MMSE) test were applied to assess participants' cognitive functions.

Results: There were 9 males and 6 females in each group. The average age of the patient and control group was 48 . The mean duration of disease in the patient group was 5 years (1-16). Mean CAG recall of the patients was $43.3 \pm 3.5$ $(40-50)$. In the patient group, attention test scores were statistically worse in both trail making test and Stroop test. In addition to these data,Ifthe patients' number of CAG repetition was increased, all the test periods were taking more time. There was also a positive correlation between CAG repetition and duration of illness and total motor scores. This was statistically significant.

Conclusion: Attention functions in HD are disturbed even in patients with mild clinic and low CAG repetition count. This not only affects the cognition but also the motor functions.
\end{abstract}

Keywords: Huntington's disease, attention, cognition.

\section{GİRIŞ}

Huntington hastalığı $(\mathrm{HH})$ otozomal dominant geçişli nörodejeneratif bir hastalıktır ${ }^{1}$.HH ile ilgili genom (IT-15)kromozom 4'ün kisa bacağında (4p16.3 )bulunmaktadır. IT-15 geni huntington proteinini kodlamaktadır. Bu genin birinci ekzonundaki CAG (citozin-adeni-guanin) tekrarlarının sayısının artmasıyla normalden fazla CAG trinükleotid tekrarı meydana gelmektedir. CAG tekrarı 40'ın üzerinde olursa hastalık ortaya çıkmaktadır. HH'ninkesin tanısı, ITP 15 geninde trinükleotid tekrar sayısının artışının gösterilmesi ile konur². Ülkemizde prevalans değeri bilinmemekle beraber Avrupa'da görülme sıklığının 100.000 'de 5-10 olduğu bildirilmektedir ${ }^{3}$.

$\mathrm{HH}$ patogenezinde; başlangıçta striatumda olmak üzere bazal ganglionlarda nöron yıkımı izlenmekte ve hastalık ilerledikçe nörodejenerasyon sonucu tüm kortekste atrofi meydana gelmektedir ${ }^{4}$. HH'li hastalar üçlü klinik triada sahiptir. Bunlar; motor, kognitif ve psikiyatrik özelliklerdir. Motor semptomlarda en sık görülen durum, hastalığın başında ortaya çıkan istemsiz hareketleridir. Psikiyatrik semptomlar (depresyon, anksiyete bozukluğu, psikoz, obsesif kompulsif bozukluk, vs.) ise hastaların \%33 ile \%76'sını etkiler. En sık görülen psikiyatrik bozukluk depresyondur. Kognitif bozukluk ise özellikle yürütücü fonksiyonlarla ilişkilidir ve hastalığın seyri sonunda demansa dönüşür ${ }^{1}$.

Dikkat fonksiyonları HH'li hastalarda klinik seyir başladıktan sonra bozulmaya başlamaktadır. Bununla beraber yürütücü işlev bozuklularl, apati, impulsif davranışlar frontosubkortikal döngü bozukluğu özelliklerini gösteren kognitif bozukluklar da hastalık seyri boyunca ilerleme gösterir ${ }^{5}$. Hastalar genellikle dikkat gerektiren performansları yerine getirmede başarısız olurlar.Bu durum hastanın bağımsızlık ölçeği, fonksiyonel kapasite ve hastalık yükünü direkt olarak olumsuz yönde etkilemektedir. HH'li hastalar için klinik performans ve kapasitelerini ölçen Birleşik Huntington Hastalığı Değerlendirme Skalası (UHDRS) 1996 yılından beri kullanılmaktadır6. 
Ülkemizde olgu sunumları dişında $\mathrm{HH}$ ile yapılmış klinik çalışma, bildiğimiz kadarıyla maalesef bulunmamaktadır. $\mathrm{Bu}$ çalışmanın amacı; genetik tanıları doğrulanmış olan HH'li hastalarda dikkat fonksiyonlarındaki bozulmayı göstermek vekontrol grubu ile karşılaştırarak değerlendirmektir.

\section{YÖNTEMLER}

Katılımcilar

Çalışmaya Erciyes Üniversitesi Tıp Fakültesi Nöroloji Polikliniğindetakip edilmekte olan 1860 yaşları arasında HH tanısı olan 15 birey alındı. Tüm hastaların $\mathrm{HH}$ tanısı genetik test ile doğrulandı (CAG tekrar sayısı 40 ve üzeri). Tüm hastaların genetik testleri Ege Üniversitesi Tıp Fakültesi Genetik Laboratuvarında yapıldı.Hasta grubu ile yaş, cinsiyet ve eğitim düzeyine göre eşleştirilmiş, çalışmaya dahil edilme kriterlerini karşılayan 15 sağlıklı gönüllü katılımcı da çalışmaya dahil edildi. Katılımcılara çalıșma ile ilgili bilgiler verildi. Ayrıcagönüllükişilerden çalışmaya katılmayı kabul ettiklerine dair onamları alındı. Bu çalışma için Erciyes Üniversitesi Etik Kurulu'ndan onay alındı (454/2017).

Çalışmada, katılımcıların bilişsel işlevlerini değerlendirmeye yönelik her birinin standardizasyon çalışması önceden yapılmış olan, Stroop Testi, İz Sürme Testi (IST) ve Mini Mental Durum Değerlendirmesi (MMDM) testlerini kapsayan bir batarya oluşturulup uyguland. Bataryanın her bir kișiye uygulanması yaklaşık 25-30 dakika sürdü.İlave olarak tüm hastalara UHDRS ölçeği de uygulandı. Buna göre; hastaların fonksiyonel kapasite, bağımsızlık ölçeği, total motor skor (TMS) ve hastalık yükü skoru (HYS) da belirlendi (HYS= [CAG-35.5] x yaş).

\section{VERİ TOPLAMA ARAÇLARI}

Mini Mental Durum Değerlendirme (MMDM)

MMDMtesti Folstein ve arkadaşları tarafından 1975 yllında geliştirilmiştir7. Bilişsel performansı değerlendirebilmek amacıyla oldukça yaygın kullanılan standardize bir testtir. Zaman ve mekan oryantasyonu, kayit hafıza, dikkat, hatırlama ve dil alanları olmak üzere 5 alt bölümden oluşmaktadır. MMDM' nin Türkçe uyarlama ve geçerlilik çalışması Güngen ve ark. tarafından yapılmıștır ${ }^{8}$. Testten alınabilecek en düşük puan 0 , en yüksek puan 30'dur. 24-30 puan arası "normal sinırlarda", 20-23 arası "hafif kognitif bozukluk", 10-19 arası "orta kognitif bozukluk", 0-9 arası ise "ileri kognitif bozukluk" olarak değerlendirilmektedir.

\section{Stroop Testi}

Stroop testi, odaklanmış dikkati, değişen taleplere göre ve bir bozucu etki altında algısal kurulumudeğiştirebilme becerisini, alışılmış bir davranış örüntüsünü bastırabilme yeteneğini ve bilgi işleme hızını ölçmektedir. Ülkemiz için standardizasyon çalışmaları TÜBİTAK'ın(Türkiye Bilimsel ve Teknik Araştırma Kurumu) Temel Bilimler Araştırma Grubu(TBAG) tarafından desteklenmiş olması nedeniyle, Stroop Testinin Türk formuna, Stroop Testi TBAG Formu adı verilmiştir.Bu test (Stroop TBAG) Karakaş ve ark. tarafından yapılmıştır ${ }^{9}$.Çalışmada kullanılan Stroop testi TBAG formu beş bölümden oluşmaktadır. Bunlar: siyah olarak basılmış renk isimlerinin okunması (1.Bölüm), farklı renklerde basılmış renk isimlerinin okunması (2.Bölüm), renkli basılmış dairelerin renginin söylenmesi (3.Bölüm), renk ismi olmayan nötr kelimelerin renklerinin söylenmesi (4.Bölüm), farklı renklerde basılmış renk isimlerinin renklerinin söylenmesi (5. Bölüm). Test puanlaması aşamasında hatalar ve süreler (saniye)kaydedilmektedir.

\section{İz Sürme Testi (İST) A Formu}

Dikkati sürdürebilme, motor hız, görsel aramatarama, işlem hızı, zihinsel esneklik ve yürütücü işlevleri değerlendirmektedir. Testin $\mathrm{A}$ ve $\mathrm{B}$ olmak üzere iki formu vardır ${ }^{10}$. Bu çalışmada, katılımcıdan 1'den 25'e kadar numaralandırılmış ve düzensiz sırada 
yerleștirilmiş 25 daireyi sıraya uygun bir şekilde kalemini kaldırmadan çizerek birleştirmesinin istenildiği A formu kullanılmıştır. Testin Türkçe geçerlilik ve güvenirlilik çalışması Cangöz ve ark. tarafından yapılmıştır ${ }^{11}$.

\section{İstatistiksel Analiz}

Elde edilen veriler Sosyal Bilimler için İstatistik Programinın (Statistical Package for Social Sciences) SPSS 22.0 sürümü kullanılarak analiz edilmiştir. Sürekli değişkenler ortalama ve standart sapma, kategorik değişkenler sayı (yüzde) olarak verilmiştir. Grup karşılaştırmalarında, parametrik testlerde Varyans Analizi ve non-parametrik testlerde ise Mann-Whitney U testi kullanılmıştır. Niteliksel değişkenler Ki-kare testi ile incelenmiştir. Değişkenler arası ilişkiyi incelemek için Pearson Korelasyon analizi kullanılmıştır.

\section{BULGULAR}

$\mathrm{Bu}$ çalışmamız; non-randomize,prospektif bir klinik çalışma olarak tasarlandı. HH'li hasta grubunda 9 erkek ve 6 kadından oluşan toplam 15 hasta vardı. Kontrol grubu içinde benzer grup oluşturuldu. Hasta grubunda (31-59) ve kontrol grubunda (31-60) ortalama yaş 48 bulundu. Yaş ve cinsiyet açısından gruplar arasında istatiksel farklılık bulunmadı ( $\mathrm{p}>0.05)$. Hasta grubunda ortalama hastalık süresi 5 yıldı (1-16). Tüm hastalar motor semptomları için tetrabenazin kullanıyordu. Ortalama CAG tekrar sayıları $43.3 \pm 3.5$ (40-50). Hasta ve kontrol grubunda yer alan katılımcılara ait demografik bilgiler Tablo l'de gösterilmektedir.

UHDRS ölçeği tüm hastalara uygulandı. Bu ölçeğin Türkçe geçerlilik ve güvenirlilik çalışması ülkemizde henüz yapılmamıştır. Ancak literatürde yer alan tüm klinik çalışmalarda uygulanmaktadır. Buna rağmen UHDRS ölçeği hastalara uygulandı ve sonuçlar tablo Il'de gösterilmektedir.

Hasta ve kontrol gruplarına dikkat fonksiyonlarını değerlendirmek için İST-A formu ve stroop testi uyguland. Hasta grubunda dikkat test skorları hem IST-A testinde ve hem de stroop testinde istatiksel olarak daha kötü (daha uzun süre) bulundu (p $<0.05$ ). Gruplara ait dikkat test skorları tablo III'de ve grafik 1'de gösterilmektedir.

Tablo 1. Hasta ve kontrol grubunun demografik verileri

\begin{tabular}{|l|c|c|}
\hline & Huntington Hastaları & Kontrol \\
\hline Cinsiyet (Erkek/Kadın) & $9 / 6$ & $9 / 6$ \\
\hline Yaş (yıl) & $48(31-59)$ & $48(31-60)$ \\
\hline Eğitim (yıl) & 9.6 yıl & 10.2 yıl \\
\hline Hastalık süresi (yıl) & $5(1-16)$ & - \\
\hline
\end{tabular}

Tablo 2. Huntington hastalığını değerlendirme ölçek puanları (UHDRS) (Sayi:15)

\begin{tabular}{|l|c|}
\hline CAG tekrar sayısı & $43.3 \pm 3.5(40-50)$ \\
\hline Fonksiyonel kapasite & $9.27 \pm 3$ \\
\hline Bağımsızlık ölçeği & $82 \pm 15$ \\
\hline TMS & $20.7 \pm 2(4-46)$ \\
\hline HYS & $356.3 \pm 184.8$ \\
\hline
\end{tabular}

UHDRS: Birleşik Huntington Hastalığı Değerlendirme Skalası, CAG:citozin-adenin-guanin, TMS: Total Motor Skor, HYS: Hastalık yükü skoru

İST-A formunun performans skorları hasta grubunda istatistisel anlaml o olarak daha yüksek bulundu $(\mathrm{p}<0.05)$. Bu sonuç grafik 2 'de gösterilmektedir.

$\mathrm{Bu}$ verilere ilave olarak, hastaların CAG tekrar sayıları artıkça,tüm test süreleri de daha fazla zaman alıyordu( $p<0.05)$. Ayrica CAG sayısı ile hastalık süresi ve TMS arasında pozitif korelasyon bulundu. Bu durum istatistiksel olarak anlamlı bulundu ( $\mathrm{p}<0.05)$.

\section{TARTIŞMA}

Yaptığımız bu çalışmada HH'li hastaların dikkat fonksiyonlarının dikkate değer bir şekilde bozulmuş olduğunu ortaya koyduk. Her iki dikkat testinde de kontrol grubuna göre performans skorları daha kötü bulundu. Bu bulgulara ilave olarak HH'li hastalarda CAG 
tekrar sayısı artıkça ve hastalık progrese oldukça bu durumun daha da belirginleştiğini gösterdik. Elde ettiğimiz bu veriler HH'nin patogenezi ve klinik seyri ile uyumlu olarak değerlendirildi. HH'de hastalık progrese oldukça, nöronal dejenerasyon (nöronal kayıp ve gliozis) bazal ganglionlardan tüm serebral kortekse doğru yayılmakta ve sonuçta dikkat ile ilgili kortiko-striatal döngüler de bozulmaktadır.

Tablo 3. Huntington hastalarının ve kontrol grubunun dikkat test skorları

\begin{tabular}{|c|c|c|c|}
\hline & Huntington hastaları & Kontrol & \multirow{2}{*}{$\mathrm{p}$} \\
\cline { 1 - 3 } & Ortalama \pm S.S. & Ortalama \pm S.S. & 0.040 \\
\hline MMDD & $24.5 \pm 4.6$ & $28.63 \pm 1.41$ & 0.032 \\
\hline İz sürme testi (A) & $111.9 \pm 74.05$ & $41.53 \pm 16.8$ & 0.042 \\
\hline Stroop 1. bölüm & $17.3 \pm 8.4$ & $9.88 \pm 2.01$ & 0.030 \\
\hline Stroop 2. bölüm & $20.1 \pm 8.97$ & $11.37 \pm 2.48$ & 0.023 \\
\hline Stroop 3. bölüm & $33.65 \pm 20.12$ & $20.5 \pm 8.46$ & 0.015 \\
\hline Stroop 4. bölüm & $46.56 \pm 23.03$ & $31.68 \pm 11.83$ & 0.014 \\
\hline Stroop 5. bölüm & $70.86 \pm 34.17$ & & \\
\hline
\end{tabular}

MMDM:Mini Mental Durum Değerlendirme

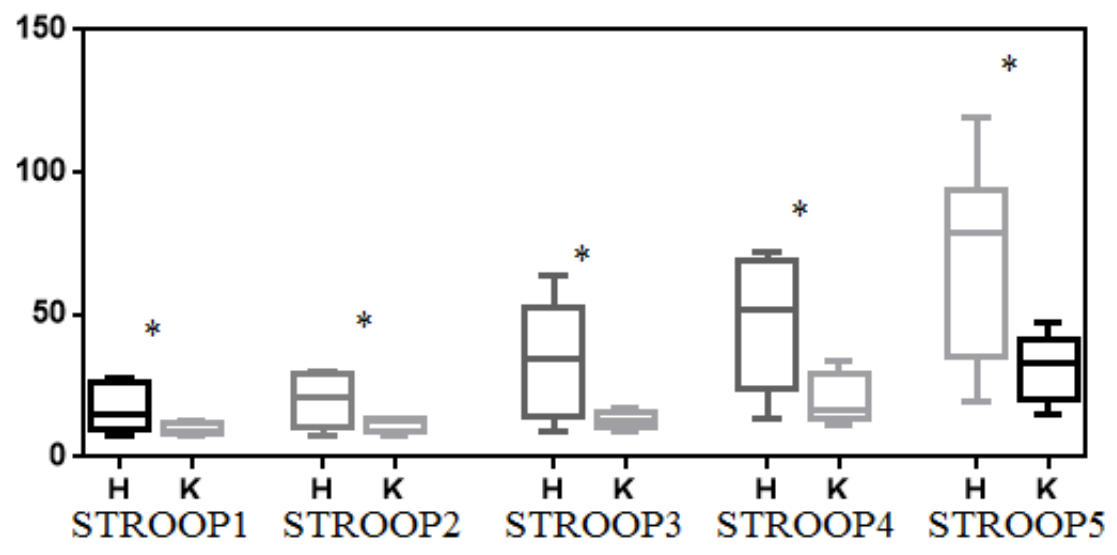

$\mathrm{H}$ : hasta, K: kontrol

Grafik 1. Hasta ve kontrol grubunun stroop test performans skorları. 


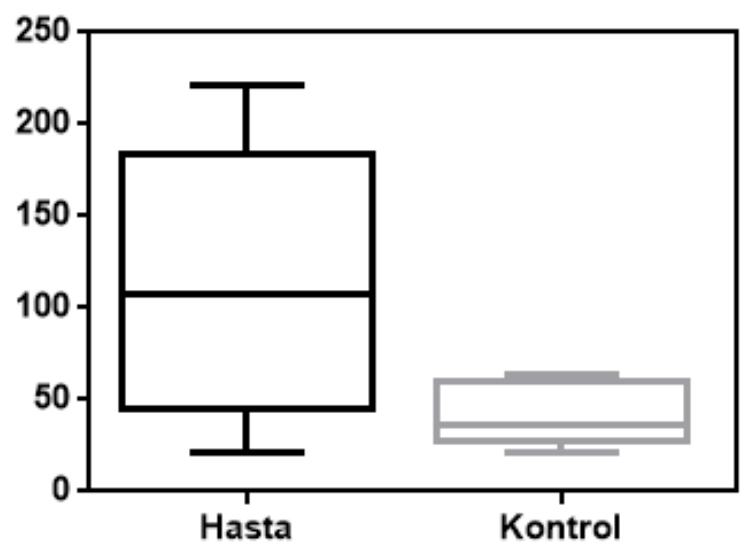

İST-A :İz Sürme Testi A Formu

Grafik 2. Hasta ve kontrol grubunun İST-A test performans skorları.

HH'da kognisyonun bozulması hastadan hastaya değişmekle beraber,düşünce hızında yavaşlama (psikomotor hız)ve yürütücü işlevlerde bozulma şeklinde başlayabilir. Hastalar tipik olarak; görev spesifik (multitask) işlerde zorlanma, işleyen bellekde (working memory-short term memory) bozukluk ve konsantrasyongüçlügünden şikayet ederler ${ }^{12}$. Bundan dolayı hastaların günlük yaşam aktivitelerinde planlama, organizasyon, reorganizasyon ve zamanlama ile ilgili güçlükler meydana gelir. Sonraki dönemlerde klinik tabloya görsel-uzaysal fonksiyonlarda bozulma ve demans tablosu hakim olmaktadır.

HH'da kognitif bozukluk üç evrede incelenebilir. Bunlar; prodromal evre, klinik evre ve demans evresidir. $\mathrm{Bu}$ evreler fonksiyonel kapasitedeki azalmayla direkt ilişkilidir ${ }^{13}$. Robins ve ark. yaptığı çalışmada 24 HH'li asemptomatik taşıyıcı bireyin kognisyon durumları incelenmiş ${ }^{14} . \mathrm{Bu}$ dönemde bile asemptomatik bireylerin dikkat, hafiza ve algılanan motor hız test skorları daha kötü bulunmuş. Sonuçta dikkat azalmasıyla birlikte kognitif yavaşlık ve hataları fark edememe veya hatalı düzeltme fonksiyonel kapasite ile direkt ilişkili bulunmuş. Klinik evrede hastalık progrese oldukça bu durum daha da ilerleme kaydetmekte ve hastalar tamamen bağımlı gelmektedir. Bizim çalışmamızda da daha ileri evrede olan hastaların (UHDRS skorları daha yüksek olan hastalar) dikkat performansları daha kötü bulundu.

HH'da kognisyon ve dikkat fonksiyonlarının değerlendirildiği çalışmalarda farklı testlerin kullanıldığı görülmektedir ${ }^{15}$. Bu testler; sembol rakam modalite testi, stroop testi, iz sürme testi A-B ve kategori akıcılık (semantik) hayvan testi gibi farklı testler kullanılmıștır. Biz bu çalışmada stroop testi ve İST-A testini kullandık. Fritz ve ark. 34 HH'da stroop ve İSTA ve İST-B testini kullanarak hastaların motor ve kognitif defisitlerini incelemişler ${ }^{16}$. TMS değeri $35^{\prime}$ den büyük olan hastalarda test skorlarının daha kötü olduğunu göstermişler. $\mathrm{Bu}$ grup hastalarda dikkat fonsiyonları ile birlikte düşme sıklığında anlamlı farklılık tespit edilmiştir.Başka bir çalışmada Delval ve ark. 15 $\mathrm{HH}$ olan hastada dikkat testleri esnasinda yürüyüş parametrelerinin daha da bozulduğunu göstermişlerdir ${ }^{17}$. Görüldüğü gibi dikkat eksikliği HH'da sadece kognitif fonksiyonları değil özellikle motor fonksiyonları da olumsuz yönde etkilemekte ve hastalık seyri boyunca bu durum artış göstermektedir.

Katılımcı sayısının nispeten az sayıda olması bu çalışmanın kısıtlı yönü olarak kabul edilebilir. Ayrica kontrol grubunda MMDM skorlarının 
biraz daha yüksek olması test skorlarını daha olumlu yönde etkilemiş olabilir.

$\mathrm{HH}$ ile yapılmış, dikkat fonksiyonlarını değerlendirenülkemizdekiilk klinik çalışma olması ve tüm hastaların teşhislerinin genetik test ile doğrulanmış olması çalışmanın güçlü yönleri olarak görülebilir.

\section{SONUÇ}

HH'da dikkat fonksiyonları kliniği hafif olan ve CAG tekrar sayısı az olan olgularda bile bozulmaktadır. Bu durum sadece kognisyonu değil aynı zamanda motor fonksiyonları da olumsuz etkileyebilmektedir.

Teşekkür

Yazarlar, bu çalışmada istatistik verilerinin analizi için Dr Ruslan Bayramov'a teşekkür eder.

Çıkar Çatışması Beyanı: Yazarlar çıkar çatışması olmadığını bildirmişlerdir.

Finansal Destek: Bu çalışma her hangi bir fon tarafından desteklenmemiştir.

Declaration of Conflicting Interests: The authors declare that they have no conflict of interest.

Financial Disclosure: No financial support was received.

\section{KAYNAKLAR}

1. Apolinário TA, Paiva CL, Agostinho LA. Intermediate alleles of Huntington's disease HTT gene in different populations worldwide: a systematic review.Genet Mol Res. 2017;16:1-16.

2. Imarisio $\mathrm{S}$, Carmichael J, Korochuk $\mathrm{V}$, et al. Huntington's disease: from pathology and genetics to potential therapies. Biochem J. 2008;412:191-209.

3. Rawlins MD, Wexler NS, Wexler AR, et al. The Prevalence of Huntington's Disease.Neuroepidemiology. 2016;46:144-53.

4. Mehrabi NF, Singh-Bains MK, Waldvogel HJ, Faull RLM. Cortico-Basal Ganglia Interactions in Huntington's Disease. Ann Neurodegener Dis. 2016;1:1007-13.
5. Jane S. Paulsen. Cognitive Impairment in Huntington Disease: Diagnosis and Treatment. Curr Neurol Neurosci Rep. 2011;11:474-83.

6. Huntington Study Group. Unified Huntington's Disease Rating Scale: reliability and consistency. Mov Disord. 1996;11:136-42.

7. Folstein, M, Folstein S, McHugh P. Mini-Mental State: A practical method for grading the cognitive state of patients from clinician. Journal of Psychiatric Research.1975;12:189-98.

8. Güngen C, Ertan T, Eker E ve ark. Standardize mini mental test'in Türk toplumunda hafif demans tanısında geçerlik ve güvenilirliği. Türk Psikiyatri Dergisi.2002;13:273-81.

9. Karakaş S, Erdoğan E, Sak L ve ark. Stroop Testi TBAG Formu: Türk kültürüne standardizasyon çalışmaları, güvenirlik ve geçerlik. Klinik Psikiyatri Dergisi. 1999; 2: 75-88.

10. Tombaugh TN. Trail Making Test A and B: Normative data stratified by age and education, Archives of Clinical Neuropsychology. 2004;19:203-14.

11. Cangöz B, Karakoç E, Selekler K. İz Sürme Testi'nin Türk yetişkin ve yaşlı örneklemi üzerindeki standardizasyon çalışması. Türk Geriatri Dergisi.2007;10:73-82.

12. Paulsen JS, Langbehn DR, Stout JC, et al.Detection of Huntington's disease decades before diagnosis: the Predict-HD study. J Neurol Neurosurg Psychiatry.2008;79:874-80.

13. Stout JC, Paulsen JS, Queller S, et al. Neurocognitive signs in prodromal huntington disease. Neuropsychology.2011;25:1-14.

14. Robins Wahlin TB, Lundin A, Dear K. Early cognitive deficits in Swedish gene carriers of Huntington's disease. Neuropsychology.2007;21:31-44.

15. Reilmann R, Leavitt BR, Ross CA. Diagnostic criteria for Huntington's disease based on natural history. Mov Disord. 2014;29:1335-41.

16. Fritz NE, Hamana K, Kelson M, et al. Motor-cognitive dual -task deficits in individuals with early-mid stage Huntington disease.Gait Posture. 2016;49:283-9.

17. Delval A, Krystkowiak P, Delliaux M, et al. Role of attentional resources on gait performance in Huntington's disease, Mov Disord. 2008;23:684-9. 
Dicle Tıp Dergisi / Dicle Medical Journal (2017) 44 (4)

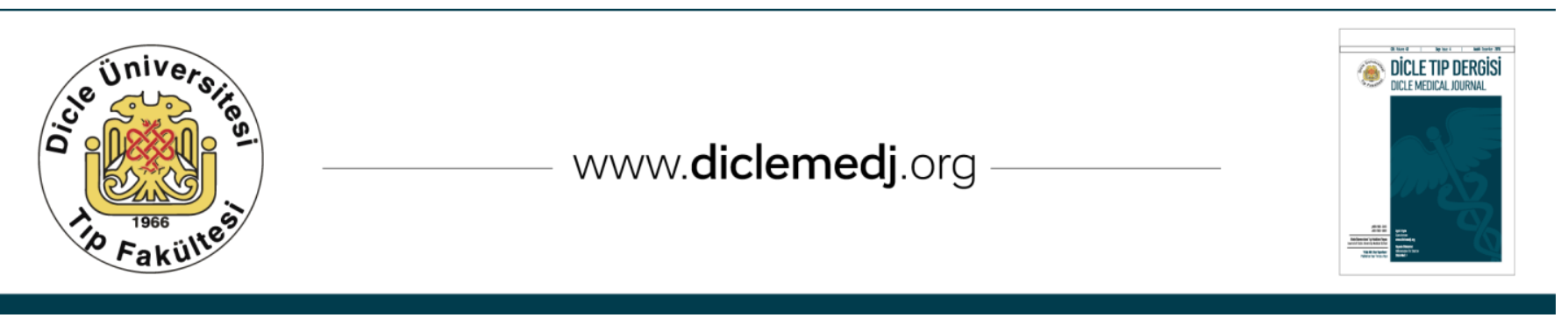

